

\title{
Suite française. Georges Didi-Huberman, uma experiência na História da arte
}

\author{
French Suite. Georges Didi-Huberman, an experiment in History of art
}

\section{Dr. Stéphane Huchet ${ }^{\star}$}

\begin{abstract}
Resumo
Os livros de Georges Didi-Huberman articulam um denso saber para produzir o que ele propôs chamar de "antropologia do visual". É uma posição de caráter neo-warburguiano, embora, no início de sua trajetória, DidiHuberman não se apoiasse em Aby Warburg, que ele ainda não tinha integrado ao seu panthéeon. Antropologia que não representa mais um risco, mas uma chance para a História da arte. As imagens artísticas, observadas e analisadas com grande atenção crítica, revelam processos que seu conhecimento aprofundado da filosofia 0 legitimam a qualificar como "dialéticos". Suas primeiras ideias e argumentações, disseminadas em vários livros que se sucederam em um ritmo anual, encontraram em Aby Warburg, por volta do ano 2000, um modelo de confirmação e consolidação. A historiografia e a filosofia da arte de Didi-Huberman foram construídas por meio de livros que privilegiam artistas, pensadores, críticos (Fra Angelico, Giorgio Vasari, Sigmund Freud, Erwin Panofsky, Georges Bataille, Carl Einstein, Aby Warburg, Alberto Giacometti, Marcel Duchamp, Walter Benjamin, Bertold Brecht, os minimalistas, Pier-Paolo Pasolini, Giorgio Agamben), que instigam uma História da arte que é uma filosofia prática da imagem e do tempo.
\end{abstract}

Palavras-chave

História da arte. Filosofia. Visual. Imagens. Iconologia.

\begin{abstract}
Georges Didi-Huberman's books articulate a dense knowledge to produce what he proposed to call "anthropology of the visual". This position has a neowarburgian character, although at the beginning of his career he did not rely on Aby Warburg, which he had not yet integrated into his pantheon. Anthropology which no longer represents a risk, but a chance for the History of art. Artistic pictures, observed and analyzed with great critical attention, reveal processes that his in-depth knowledge of philosophy legitimizes him to call "dialectic". His first ideas and arguments, disseminated in several books that followed each other at an annual pace, found in Warburg, around 2000, a model of confirmation and consolidation. Didi-Huberman's historiography and philosophy of art were built through books which privilege artists, thinkers, critics (Fra Angelico, Giorgio Vasari, Erwin Panofsky, Sigmund Freud, Georges Bataille, Carl Einstein, Aby Warburg, Alberto Giacometti, Marcel Duchamp, Walter Benjamin, Bertold Brecht, os minimalistas, Pier-Paolo Pasolini, Giorgio Agamben) who instigate a History of art which is a practical philosophy of image and time.
\end{abstract}

Keywords

History of art. Philosophy. Visual. Pictures. Iconology. 


\section{Prélude}

Escrever sobre Georges Didi-Huberman não é fácil porque sua obra transita por campos que podem, às vezes, se ignorar: a história da arte, a filosofia, a psicanálise. Ela investe também, desde suas origens, num amplo corpus bibliográfico (seus livros apresentam sempre um volume considerável de notas de rodapé). Citar os principais autores que ele leu, analisou, assimilou, reavaliou e transformou em parceiros indestronáveis de seu pensamento já é um desafio. Andar e pensar com Plínio, o Velho, teólogos antigos e medievais, Giorgio Vasari, Johann J. Winckelmann, Jacob Burckhardt, Friedrich Nietzsche, Sigmund Freud, Erwin Panofsky, Georges Bataille, Carl Einstein, Walter Benjamin, Aby Warburg, Bertold Brecht, Giorgio Agamben e, hoje, Ernst Bloch; consagrar tantos textos a tantos artistas, como Fra Angelico, Marcel Duchamp, Alberto Giacometti, Giuseppe Penone, Simon Hantaï, Pascal Convert, Pier-Paolo Pasolini, Harun Farocki, Jean-Luc Godard; diversificar os territórios de estudo, que vão da teoria greco-romana da imagem às relações ambíguas de Agamben com Carl Schmitt etc., justifica que consideremos impossível produzir qualquer soma crítica de sua obra.

Georges Didi-Huberman é um autor que tem uma estética própria. Ele a projeta através de uma escrita na qual o peso do conceito e o peso do estilo se equilibram para gerar um texto sempre legível, inclusive didático. Apresenta certo tom de gravidade, que equilibra a paciência, heurística, necessária a toda argumentação, e enunciados que fazem brilhar o que eu chamarei de constelação crítica. 0 texto didihubermaniano é um verdadeiro método que abre seu portal nas primeiras páginas de todo livro. Ele as transforma num ato literário, nunca desprovido de certa solenidade, apresentando nelas sua filosofia da pesquisa e sua filosofia do objeto. Esse portal procura instigar, e até seduzir, graças a uma prosa que progride de modo seguro. Sua fala, lenta e segura, tece sua teia. Ele procede como Simon Hantaï, o artista que motivou um livro de sua autoria (L'Étoilement), no qual ele afirma que o pintor, "para encontrar as palavras de sua prática, de sua imersão pictural, atravessa os dicionários e as etimologias para cavar, aqui e acolá, uma palavra que seja fecunda, isto é, arqueológica e insensível à contradição" (Didi-Huberman, 1998a: 29). Não que Didi-Huberman goste de silenciar seus interlocutores, mas, como filósofo, ele consolida livro após livro uma autoridade intelectual que se fundamenta num subsolo sempre mais profundo. Didi-Huberman gosta de começar por uma filosofia generalista, que desliza sem demora numa filosofia regional e na filosofia local que seu objeto exige. Seu ideal filosófico e sua ambição intelectual se encontram no conceito de "imagem dialética", referência-fonte de que toma posse em 0 que vemos, o que nos olha, de 1992. Como afirma em Diante da imagem, dois anos antes, "como Warburg, Benjamin terá colocado a imagem (Bild) no centro nevrálgico da "vida histórica"' (DidiHuberman, 2000: 91). Desde então, o pensamento de Walter Benjamin nunca deixou de acompanhá-lo como uma figura tutelar: hoje, a agenda da "organização do pessimismo" deve tudo ao filósofo alemão. Em Sobrevivência dos vaga-lumes, por exemplo, a oposição entre horizonte de luz apocalíptica, relacionada com a filosofia de Agamben, e luzes intermitentes das imagens ainda portadoras de esperança, serve a pensar à altura do desafio benjaminiano. É a convicção de que "não há história possível sem teoria do "inconsciente do tempo" (Ibidem: 95) que faz de Benjamin o principal parceiro de um historiador que edificou pouco a pouco um pantheon de figuras tutelares, efígies generativas e protetoras que voltam, como leitmotiv, de livro em livro, transformando cada um deles em eterno retorno do mesmo, repetição que reinaugura e reafirma constantemente o caminho. Sua obra é análoga à "anamnese" de que fala a propósito da escultura de Giuseppe Penone: ela molda e modela seu material, "cria uma passagem para formas com memória de seu devir, de seu nascimento e crescimento futuros" (Didi-Huberman, 2009: 56). A obra é caracterizada por uma insistência, que gera autoridade, porque sabe investir e projetar sua própria memória. Um amplo capital discursivo frutifica. Didi-Huberman reafirma em Diante do tempo que sempre é preciso reiniciar a História da arte, reiniciar sua movimentação epistemo-crítica. Seu método passa pela relação "diferença - repetição" - ao "repetir", 
Didi-Huberman mantém um ritmo e evita qualquer risco de pane -, o que configura uma obra sinfônica, com frequentes reenunciações dos temas e com inúmeras variações sobre um tronco comum. A harmonia geral traz densas dissonâncias programáticas, mas elas soam dentro de um discurso que, por mais contrastado que seja, não deixa de respeitar uma tonalidade didática. Para propor outra analogia, diríamos que seus livros conseguem, como Mozart dizia de seus concertos para piano e orquestra, satisfazer tanto os conhecedores quanto proporcionar aos amadores uma apreensão razoavelmente fluida... Didi-Huberman não martela. Ele envolve progressivamente. Sua filosofia do tempo exige tempo; ressoa no tempo... O tempo que ressoa, ressoa de longe... É assim que Plínio, o Velho, já evocado em $A$ pintura encarnada, volta, 15 anos depois, para contribuir para uma "arqueologia do anacronismo", em Diante do tempo. É assim que Aby Warburg, já timidamente evocado numa breve narrativa do ano 1996-97, ainda motiva a leitura da sobrevivência dos gestos ancestrais no "cinema de poesia" de Pasolini, 15 anos mais tarde. É assim que Walter Benjamin ainda motiva, 18 anos depois de O que vemos o que nos olha, a argumentação central de Sobrevivência dos vaga-lumes. Três nomes, três pilares, formam a tríade nominal de sua obra: Panofsky, Benjamin e Warburg. Uma frase o explica: "entre Panofsky e Benjamin, é portanto todo o destino da história da arte que, a partir do tronco comum warburguiano, se põe a bifurcar" (Didi-Huberman, 2000: 98). Mas, de onde vem Didi-Huberman?

As revoluções epistemológicas realizadas na historiografia francesa da arte dos anos 1960 permitem entender como seu trabalho herdou, desde suas origens, a existência de um belo campo interdisciplinar. Este último já tinha demonstrado toda sua fertilidade quando Didi-Huberman publicou seu primeiro livro, em 1982, sobre Jean-Martin Charcot e as imagens da histeria. Nessa data, ele era um desconhecido, mas não seus ilustres predecessores: no campo da História da arte, lembraremos Louis Marin e Hubert Damisch, cujas obras mereceriam um amplo trabalho de tradução. A linguística, a semiologia, a psicanálise, o "estruturalismo", as ciências humanas em geral, contribuíram para modificar profundamente a História da arte que se escrevia na França ${ }^{1}$. Uma intensa inquietação teórica determinou um tipo de texto inédito, um tipo de abordagem e de questionamento alimentados por instrumentos críticos e por conceitos que muitos considerariam ainda hoje como externos à História da arte. Os livros que Marin e Damisch publicaram entre o fim dos anos 1960 e os anos 1980 inventaram uma nova discursividade, uma nova escrita, novas perspectivas ${ }^{2}$. Didi-Huberman trabalha sob o olhar dos pares que o precederam, notadamente a ala germânica da disciplina. Parecem presidir à obra de Didi-Huberman, como os ex-votos dos ancestrais pendurados no atrium da domus romana. Aliás, a quase totalidade da sua obra, entre meados dos anos 1980 e meados dos anos 2000, consistiu em reler e discutir a metodologia e a epistemologia das figuras tutelares da disciplina.

\section{Allemande}

A diversidade dos interesses de Didi-Huberman desenha as curvas de uma espiral. A direção da espiral não engana. Desde 2009, alguns livros giram em torno da figura(ção) do cinema, do vídeo, da fotografia, da fotomontagem, levantando questões indissociavelmente políticas e artísticas internas a uma filosofia da história e do tempo presente - uma filosofia icônica da história e uma filosofia histórica das imagens: L'œil de l'histoire - O olho da história -, vol. 1 a 5 (Didi-Huberman, 2000-2015) e Sobrevivência dos vagalumes (Didi-Huberman, 2011). É nesse último livro que a questão do "político" se mostra mais patente (mesmo se podemos considerar que todas as revisões epistemológicas já constituíram antes uma "política" da disciplina). A série traz um autor para quem as imagens são tomadas de posição política (Quando as imagens tomam posição, como diz o título do primeiro volume da série $\mathrm{O}$ olho da história), o que favorece a problematização dialética de seu funcionamento crítico, social etc., seja com Harun Farocki, seja através da oposição entre as luzes intermitentes da imagem dialética e o horizonte apocalíptico presente nos filosofemas de Agamben, ou, ainda, da oposição entre um Godard mais 
ideólogo e um Pasolini atento às sobrevivências gestuais e arcaicas na cultura italiana. Antes, entre meados dos anos 1990 e o início dos anos 2010, uma grande onda pós-psicanalítica e neo-nietzcheana sacudiu, mediante a figura tutelar de Warburg, uma História da arte em perpétuo processo de redefinição e reafirmação de suas tarefas. Mas essa fase, que continha sua própria política epistemológica, ao transitar por figuras-chave como Benjamin, Carl Einstein, Georges Bataille, Michel Leiris, prolongava um momento anterior consagrado à questão da figura como crise. Os dez anos entre 1982 e O Cubo e o rosto (1993), viram uma série de livros ou artigos (Didi-Huberman, 2012) realizarem uma desconstrução da representação e a promoção de vários conceitos em desuso na historiografia tradicional, exatamente por ela ser historiografia e só historiografia. A crise da figura foi um mote para pensar as condições de transformação das imagens numa "aparição" (termo de origem fenomenológica que demonstra tudo o que Didi-Huberman deve a essa família filosófica). A crise da figura é uma crise reveladora. Ela propicia a possibilidade de pensar como a arte é "uma experimentação e uma teoria da maneira pela qual as figuras não somente "representam", mas se "apresentam", nascem, se combinam e se contradizem para contar várias estórias ao mesmo tempo" (Didi-Huberman, 1998c: 96).

Isso justifica seu combate contra a iconologia, que ele já define num ensaio de 1986 como "um modelo epistémico que exige a estabilidade lógica dos objetos representados", assim como sua "estabilidade semântica" (Ibidem: 84). Esse combate explica também a importância que Didi-Huberman deu a um conceito devendo muito à teologia, o de "dessemelhança". Esse conceito the permite levar o conceito de "semelhança" - central tanto na concepção popular da representação quanto na seleção de seus objetos pela iconologia -, "no elemento crítico e problemático, inevidente, de seu surgimento" (DidiHuberman, 1990c: 18). A filosofia que sustenta a eleição desse conceito intempestivo repousa sobre a conviç̧ão de que a dessemelhança "obceca e gere o olhar do homem desde mais tempo que se imagina" (Ibidem: 20). Conceito de uma transversalidade histórica, a dessemelhança oferece uma "lição": "o objeto do olhar não nos é dado, mesmo quando acreditamos abarcar as coisas quando as olhamos... Pois, o objeto se relaciona com um desejo" (Ibidem: 21). Mas onde Didi-Huberman encontrou a dessemelhança? Em pinturas ou mármores, imagens ou afrescos que puseram sua percepção num estado de suspensão, de dúvida, de intenso afeto estético e crítico, às vezes espiritual. Nessa década, a temática do sonho e da figurabilidade é o correlato de um exercício do olhar que revela em DidiHuberman um desejo de imagem bem singularizado. Para um historiador disposto, as obras podem "se dar" e, nessa experiência, o historiador experimenta um contato e uma experiência similares ao contato e à experiência do artista com o visível. Analisando a escultura de Alberto Giacometti em 0 Cubo e 0 rosto, Didi-Huberman afirma como o artista, antes de a obra ser iniciada, sentiu-se "olhado pela perda de um rosto cujo nome era seu" (Didi-Huberman, 1993: 115), o do pai. O Cubo, do ano 1934, constituiu assim a "abertura dialética" (Ibidem: 115) desse enigma/olhar.

Uma frase resume a intenção originária de Didi-Huberman perante o enigma das imagens e a necessidade de criticar a iconologia: "as soluções de enigmas são sempre sintagmas fechados" (Ibidem: 114). Didi-Huberman combate incansavelmente os fechamentos. Poderíamos multiplicar os momentos nos quais ele precisa opor uma tese e uma antitese, antes de propor a superação dialética do impasse (dialetizar, por exemplo, "o modelo histórico do Renascimento e o modelo anacrônico das sobrevivências" (Didi-Huberman, 2002: 86); retirar a História da arte "do historicismo (em busca da unidade de tempo) e do esteticismo (em busca da unidade de estilo)" (Ibidem: 81). A iconografia tradicional, ao solucionar os enigmas da imagem, transforma a solução em sintagma fechado. E DidiHuberman acrescenta: "é évidente que essas soluções não eram soluções: elas tendiam tanto a esconder quanto a revelar, tanto a silenciar quanto a dizer" (Didi-Huberman, 1993: 114). Essa frase significa que a análise tradicional das imagens, ao revelar seu sentido, silencia e esconde outras 
dimensões. No revelado e no dito, a iconografia acaba desarmando o poder disruptivo daquilo que a revelação e o dito esclarecem. Toda a obra de Didi-Huberman, desde o início, é uma grande rapsódia que reclama para as zonas escuras da imagem, da arte, da cultura e, por extensão, da vida humana, 0 direito de significar. A contemplação desse direito explica que seus primeiros livros já sejam dedicados - em favor de uma outra relação com as imagens - a uma crítica ardente dos comportamentos e dos métodos consagrados pela historiografia "universitária". A realização dessa crítica epistemológica exige uma caça permanente para encontrar, ler, analisar e promover textos e autores que 0 ajudam a legitimar sua pesquisa dentro de uma disciplina ainda insuficientemente flexível. Daí a necessidade de desocupar o terreno no próprio campo da História da arte. É a isso que Didi-Huberman consagrou toda sua energia desde que ele inaugurou seu trabalho com o estudo das fotografias da histeria.

Metaforicamente, referindo-nos a um conceito de Michel Foucault, podemos dizer que ele faz a loucura voltar na razão historiográfica, uma "loucura" epistemológica, decerto dominada numa linguagem sofisticada. Para tornar tal volta possível, Didi-Huberman propõe: em primeiro lugar, devolver vida e pertinência às "margens" críticas da tradição. É seu lado genealogista e hermeneuta. A título de exemplo, dispomos do grande portal crítico constituído pela primeira parte de A imagem sobrevivente. Nela, Didi-Huberman ressitua a História da arte e a Doutrina artística de Winckelmann numa perspectiva ela mesma neo-vasariana; ele consagra, depois, muitos capítulos ao contexto epistemológico no qual Warburg se formou e ao recalque de que foi objeto desde sua morte, transformando-o em "fantasma" da disciplina. Essas cem páginas são incontornáveis para toda epistemologia histórica; em segundo lugar, propõe "importar" conceitos de outras áreas com o intuito de que existe um sujeito da/na arte. É seu lado psicanalista, quando Freud lhe permite enxergar, por meio da ideia de uma transferência do paradigma clínico no plano crítico, comportamentos icônicos similares aos sintomas psíquicos. (Carl Einstein e Aby Warburg virão depois confortar essa proposta). É o sujeito da arte que interessa a DidiHuberman desde que trabalha a retirar a pintura de sua apropriação tradicional e de sua redução a uma mera plataforma de informações culturais. Didi-Huberman restaura a substância, mas uma substância dilacerada, viva, explosiva, expressiva, expelida, dobrada, redobrada. Algum pli dans l'ouvert, alguma dobra no aberto, que demonstra que, desde o início, Didi-Huberman tem uma atitude artista, quando são as imagens e outros fenômenos visuais, não necessariamente artísticos, que despertam sua inquietação crítica de historiador. Detemo-nos alguns minutos em Phasmes (1998), que constitui uma espécie de condensado da obra, tanto por seus temas, diversos, quanto pela sensibilidade de que testemunha.

\section{Courante}

Phasmes é constituído por uma série de ensaios que resultam do maravilhamento como fonte de despertar e do disparo da pesquisa. Phasmes é um ateliê a céu aberto, o laboratório intelectual do autor, uma matriz. É nesse livro que assistimos à volta dos fantasmas formais - das Pathosformeln - na breve narração de um passeio na Piazza Navona, em Roma, na época do Natal, quando enigmáticas figuras de cera vendidas para os presépios the lembram figurinhas e ex-votos etruscos vistos num museu vizinho. Julius von Schlosser é citado, e Warburg, en passant. Retrospectivamente, o mercato di figurine romano se mostra como um lugar e um momento significativos no despertar crítico que o livro sobre Warburg confirmará alguns anos mais tarde. É em Phasmes que encontramos também um ensaio datado de 1988 - bem na linha daquilo que ele investigava naquela época - que analisa a concepção agostiniana da imagem. Didi-Huberman encontra no autor das Confissões "uma crítica do mundo visível" (Didi-Huberman, 1998c: 124) e a teoria de "um sujeito dividido, um sujeito fadado à dissociação do ver pela natureza mesma da exigência que lhe [é] submetida: ver além dos corpos visiveis" (Ibidem: 124-125). E vem uma frase extraordinária na qual Didi-Huberman afirma que 
é preciso maravilhar-se que uma civilização inteira tenha sido capaz de fazer expressamente da dissociação - essa infelicidade, essa convulsão - a condição necessária a todo alçar voo do pensamento. E esse alçar voo tomará a forma de um combate, que é um combate do sujeito contra seus próprios olhos. Ora, é precisamente aqui que Agostinho se mostra comovente, universal: (...) ele abria uma análise infinita sempre reconduzida, involuída, ofegante, soberba, refluxiva, das dificuldades do ser da visão, quando o Ser se vê postulado além do ver. Agostinho fundava assim uma verdadeira antropologia do desejo (Ibidem: 125)

Como não enxergar neste pequeno trecho, que destacamos entre centenas de frases que mereceriam, todas, nossa meditação, a identificação de um programa crítico e o anseio de situar a História da arte, entendida, sabemos, como antropologia do visual, à altura dos desafios filosóficos já encontrados, no século V, no conceito de homem compuctus de Agostinho, isto é, o homem "ferido, aflito, dissociado" (Ibidem: 124)?! As teorias greco-romanas da imagem e do retrato e, na continuação da epistemé antiga, a Patrística cristã, constituem lugares-chave na determinação filosófica do sentido das imagens. Nelas, Didi-Huberman encontra os elementos genealógicos que permitem pensar certas categorias filológicas e simbólicas como a mimesis, as "fantasmata", o diáfano, a imago, a epifania etc. Em Phasmes, encontramos também Filoteu de Batos, que inventou, entre os séculos IX e XII, o verbo "fotografar", ou tal xilogravura alemã do ano 1470 que já procede segundo o mecanismo da montagem para visualizar a Chaga de Cristo. Aqui, o "corpo cristão" cuja esquize ontológica, segundo Didi-Huberman, teria sido formulada por Agostinho, encontra seu modelo topológico:

endoscopia paradoxal de um corpo que permanece ausente (...) a montagem inventa contatos inauditos [e faz] do corpo venerado um organismo literalmente "incrível", ao mesmo tempo decomposto e recomposto. (...) A montagem dramatiza e focaliza o olhar. (Ibidem: 190)3.

Todo Didi-Huberman consta nessa frase. A montagem vai se tornar em seguida uma categoria epistemológica motora, cujas origens me parecem exigir que não se a reduza a seu plano apenas filosófico, sendo ela, antes, uma categoria artística e estética: a reencontramos na soma sobre Warburg, em 2002, na análise do Jornal de Guerra de Bertold Brecht, em 2010, no livro sobre Godard, em 2015.

Phasmes, além de seu caráter de coletânea de ensaios, por ser uma espécie de caderno de esboços ou micro-exposições das raízes e das ramificações da obra, procede de uma montagem crítica em curso. Phasmes problematiza o efeito estético e teórico de encontros imponderáveis com objetos e fenômenos que a abertura antropológica e epistemológica permite abordar como material de uma experiência. Aquilo que será investigado terá, antes, aparecido ao historiador e despertado seu olhar. A prática do historiador é assumidamente renovada através de uma filosofia do encontro. Como afirma Didi-Huberman na primeira página do livro,

aquilo que a coisa inesperada é incapaz de oferecer - uma resposta aos axiomas da pesquisa enquanto demanda feita ao saber -, ela o reelabora, alhures e de modo outro, como dom: numa abertura heurística, numa experimentação da pesquisa enquanto encontro. Outro gênero de conhecimento (Ibidem: 9-10).

Tal é o lado ao mesmo tempo hiper-crítico e hiper-sensível desse historiador que nunca renuncia à sua sensitividade para legitimar sua obra, com o risco de certo preciosismo, bem característico de uma atmosfera sensorial que nos permitimos qualificar de "francesa". E, muitas vezes, esses encontros inspiram livros menores, mas não menos importantes, como Ser Crânio (2000), sobre a obra de Giuseppe Penone, ou 0 estrelamento. Conversa com Simon Hantaï, em que faz rimar estrela e tela, 
estrelamento e "entelamento": ele propõe uma fenomenologia do tecido, da trama, e leva o leitor na densidade de um conceito que Derrida havia estudado, dez anos antes, a partir dos desenhos de Artaud, o subjectile, e que permite explorar toda uma topologia da interface frente/verso, uma materialidade tátil, uma estética da invaginação, uma reflexão pós-deleuziana sobre a plástica da dobra etc. É nesse tipo de livro que Didi-Huberman reafirma sua conaturalidade com o artista: quando ele escreve que a pintura de Hantaï, nos anos 1950, "terá procurado aquele contato [com o subjéti] e aquela "subida" da tela por todos os meios, isto é, através de um campo - experimental - de paradoxos encadeados" (DidiHuberman, 1998a: 30)4; eu leio em filigrana uma autodefinição do seu método por Didi-Huberman. 0 que ele ressalta nos artistas é sua capacidade de "encarnar as questões mais essenciais" (DidiHuberman, 2009: 36). Esses livros de formato menor são os marcos de uma respiração intelectual, de pausas e meditações mais livres, sem que o extremo rigor do pensamento seja jamais abandonado. Constituem tábuas de jogo com enigmas artísticos ou visuais em torno de categorias que os subtítulos indicam: nudez, sonho, crueldade (Ouvrir Vénus, 1999); lugar, contato, pensamento, escultura (Être Crâne); ar, pó, impressão (Génie du non-lieu, 2001); corpo, fala, sopro, imagem (Gestes d'air et de pierre, 2005); imagem, órgão, tempo (Ex-Voto, 2006) etc. Em muitos desses livros, as manifestações mais contemporâneas ou remotas das artes plásticas motivam uma série extremamente sólida de textos que eu caracterizaria de neo-antigos, formando ecos a textos como 0 Diáfano, de Aristóteles, ou ao famoso Livro XXXV da História Natural de Plínio sobre a pintura, uma fenomenologia e uma topologia, uma poïesis da matéria, dos tecidos, das superfícies, dos volumes, da película, da dobra, da impressão, em torno de múltiplos topoï. Esses livros constituem a parte mais mágica de sua obra. Eles envolvem algo que a introdução de $A$ pintura encarnada, em 1985, apresentava como jogo de complementaridade e equilíbrio entre uma semiologia e uma fenomenologia. Confirmam também a importância estratégica de reavaliar e revalorizar a percepção no trabalho do historiador. Todos demonstram a necessidade de o historiador se colocar frente ao motivo - como Cézanne ao pé da Montagne Sainte-Victoire - sem jamais renunciar à sua bagagem epistemológica.

0 sucesso de seus livros, notadamente junto dos artistas, reflete a capacidade rara de o historiadorfilósofo produzir um corpus de saber, dosando perfeitamente a interdependência do conceito e da singularidade icônica. Aqui, deveríamos mencionar a exposição L'empreinte, realizada em 1997 no Centre Georges Pompidou, e seu catálogo (Didi-Huberman, 1997), cujo texto é uma meditação magistral sobre todos os registros estéticos, semiológicos, fenomenológicos, plásticos, da empreinte, da impressão, uma indagação que não deixa nenhum resto, uma investigação total nas dimensões matriciais, modelagem e moldagem, em períodos clássicos, até um Duchamp "anacrônico"... Uma antropologia e uma fenomenologia do contato e da visão, da matéria e da enformação, da fôrma e da forma, do rastro e da re-produção, dos modos de plasmar o tempo e os corpos etc., motivam uma ichnografia e ichnologia - como já evocamos en passant no prefácio a $O$ que vemos o que nos olha (1998) -, opostas à iconografia 5 . Para isso, Didi-Huberman, volta mais longe que o tempo de Plínio: ele remonta até a Pré-história, para acabar com Bruce Naumann... Esse conjunto de textos, que demonstra a finíssima atenção que Didi-Huberman reserva à criação artística, autoriza-nos a defini-lo como um exímio crítico de arte e um exímio clínico de arte porque sua atenção e sua capacidade de escrever sobre os aspectos mais recônditos da tatilidade sustentam a ambição de tocar o lugar do pensamento, como diz em Ser crânio. É, sem dúvida, essa inquietação e busca constantes de adentrar 0 pensamento(-imagem) que o tornam mais que um simples historiador da arte, mesmo se é principalmente na História e na Teoria da arte que ele tece seu caminho filosófico. 


\section{Sarabande}

Didi-Huberman não tem restrição de épocas. Ele transita com a mesma facilidade na arte e na cultura medievais, na arte e na cultura clássicas, na arte e na cultura modernas, na arte e na cultura contemporâneas. Ele veicula, de maneira nativa, uma filosofia implícita da possível co-existência transtemporal das categorias artísticas: é o que demonstra a famosa articulação anacrônica das camadas do tempo em Diante do tempo, ou, como já indicamos, em $A$ imagem sobrevivente, lembrando que o campo de paradoxos plásticos e topológicos experimentado na exposição e no catálogo L'Empreinte já tinha disparado o motor dialético do "anacronismo"... O esforço é enorme porque ele parte do campo disciplinar da História da arte, de sua tradição crítica, da mais antiga e clássica Teoria da arte, para caçar, deslocar e remanejar as categorias, resgatar o esquecido, revalorizar conceitos negligenciados, recarregá-los de energia epistemológica, pô-los a trabalho, refuncionalizá-los. DidiHuberman discute passo a passo as teses dos historiadores e propõe uma rememoração da grande constelação alemã do "anacronismo", que corresponde à passagem do século XIX para um século XX já bem avançado. Esse processo procura notadamente descontaminar a História da arte de suas próprias metodologias positivistas, das metodologias e das filosofias vindas da prática e da ciência histórica em geral, respondendo assim a uma pergunta que se revela muito delicada no caso brasileiro, a História da arte tendo sido durante muito tempo considerada um sub-membro, periférico, da História: "fazer história da arte, seria como fazer história ?" (Didi-Huberman, 2000: 27), pergunta, em itálico... É por meio da menção da grande época de Burckhardt, Aloïs Riegl, Heinrich Wölfflin e Aby Warburg que Didi-Huberman conclama para a renovação de uma disciplina que saberia ser "filosoficamente audaciosa [e] filologicamente rigorosa" (Ibidem:27), transformando a imagem em "conceito operatório e não em simples suporte da iconografia" (Ibidem: 48).

A iconografia entendida como "soluções de enigmas" geradoras de "sintagmas fechados" exigia, portanto, interrogar sua legitimidade e sua longa vigência. Tais soluções não representam "verdades interpretativas, mas elementos a mais a interpretar" (Didi-Huberman, 1993: 114), escreve DidiHuberman. Nessa frase, encontramos em poucas palavras a razão de um deslizamento crítico fundamental na obra de Didi-Huberman: a contestação da verdade iconológica, como verdade da disciplina historiográfica, legitima o questionamento de seus postulados teóricos e práticos bem como uma constante vigília perante os riscos de recaída nos "sintagmas fechados". Os "enigmas" iconográficos que seus livros nunca deixarão de investigar respondem à injunção de o historiador tomar em consideração "aquilo que se encontra ao mesmo tempo erguido na nossa direção e deitado sob nosso olhar" (Ibidem: 166)... É preciso, portanto, voltar às origens...

Se Didi-Huberman se diz à procura, desde o início, da "exuberância, complexidade e sobredeterminação das imagens" (Didi-Huberman, 2000: 16), é com a pintura que sua meditação começou. Cinco anos depois do livro mais singular que jamais escreveu: A pintura encarnada (DidiHuberman, 1985; 2012), o ano 1990 nos coloca frente a um nó bibliográfico bem marcado, um momentochave de sua reflexão. Com efeito, é o ano de publicação do Fra Angelico (Didi-Huberman, 1990b) e de Diante da imagem (Didi-Huberman, 1990a; 2013). O primeiro constitui um livro ainda próximo da tradição iconológica. As pinturas de Angelico ou de outros pintores do século XV geram uma sólida investigação naquilo que Panofsky considerava constitutivo do terceiro nível da iconologia, o do sentido cultural e da simbolicidade das obras. $O$ que Didi-Huberman tenta demonstrar é que o rastreamento sábio do sentido das obras pelos iconólogos de cunho panofskyano não sabe ver - porque não quer ver - nas imagens o que nelas reenvia a dimensões paradoxais ${ }^{6}$. O paradoxo é o seguinte: é como bom iconólogo - um iconólogo que recorre à erudição e à análise das fontes bibliográficas da época, um iconólogo que recontextualiza tudo -, que Didi-Huberman mostra que é preciso saber muito para 
desconstruir o silêncio de um certo saber historiográfico sobre as supostas áreas de não-saber presentes nas obras. Em Fra Angelico, ele põe a solidez metodológica da iconologia ao serviço de sua perturbação. Pretende "driblar" o discurso que só valoriza a legibilidade e a verbalidade do visível. Ora, mostra Didi-Huberman, a pintura de Angelico é repleta de signos visuais que escapam à captura lógica ou, melhor dito, ela é repleta de signos visuais cuja lógica não é exatamente declarativa, no sentido que esse termo adquirirá mais tarde na teoria vasariana da arte: esses signos funcionam como sintomas.

Fra Angelico e Diante da imagem são dois livros sobre o sintoma na pintura (Freud), o sintoma que 0 ocupa desde que sua obra se inicia e que aparece ainda com tanta força 20 anos depois no livro sobre Warburg, em 2002. Se Fra Angelico nos faz atravessar o amplo corpus teológico medieval é para mostrar como é preciso abrir o olhar do historiador sobre dimensões extra-racionais e enxergar sua manifestação na imagem. Como a argumentação procede de maneira iconológica, Fra Angelico constitui, portanto, a última concessão que Didi-Huberman faz à historiografia tradicional, seu "adeus" a ela. 0 método iconográfico serve a sair do ideal iconológico. A iconologia serve a sair da iconologia. Concomitante e logicamente, Diante da imagem realiza, no plano mais concentrado da epistemologia, o que Fra Angelico fazia através da análise de - e da renovação do olhar crítico sobre - uma obra circunscrita.

Os dois livros se respondem, como que num eco polifônico. Diante da imagem é um livro fundador porque ele procede a um ataque regrado contra o modelo iconológico e suas fontes antigas ${ }^{7}$. DidiHuberman demonstra que Panofsky seria o genial revezador de uma tradição que teria começado na época de Vasari, quatro séculos antes, uma tradição crítica caracterizada por um "tom metafísico". Reconstruindo - e respondendo assim a - um nó transtemporal, reunindo o fundador da História da arte na Renascença e seu mais detido analista moderno - o Panofsky de ldea ${ }^{8}$-, Didi-Huberman tenta desmontar a metafísica artística da ideia ${ }^{9}$. Se ele a critica com tanta força é porque ela seria incapaz de reservar seu devido lugar aos "comportamentos" imponderáveis e dessemelhantes da imagem. Toda a temática do "pan" (pano de muro ou de pintura), da mancha (que tem sua importância na teoria e na arte do século XX), do derrame pictórico, do "entrelacs" (entrelaçamento), da treliça de superfície, criaram, já nos anos 1980, uma nomenclatura crítica que encontrava nas imagens pintadas signos de um não-saber, algo de pré-verbal, uma espécie de estado primário da produção icônica. Primeiro grande marcador epistemológico, Diante da imagem, investiga o "inconsciente da representação" (DidiHuberman, 2000: 40): notemos que essa fórmula data de dez anos depois, do ano 2000, em Diante do tempo, que constitui o segundo grande marcador de sua obra, quando Didi-Huberman reiteira, através de uma rede crítica muito mais ampla e amadurecida, as características do savoir historien, o "saber historiador": que, frente às imagens, não se encontram apenas data, nem o passado, mas a memória; e que essa memória é "montagem" - eis a palavra das duas futuras décadas - do tempo e do saber...

\section{Bourrée}

Essa posição autoriza retomarmos a possível analogia entre o exercício da genealogia em Foucault e a genealogia didi-hubermaniana dos conceitos mais recônditos, esquecidos ou negligenciados da História da arte, tesouros epistemológicos perdidos no arquipélago do tempo. Podemos enxergar, na desconstrução do ideário metafísico na/da História da arte alguma similaridade, algum parentesco com a reinvindicação foucaultiana de identificar em quaisquer epistemé, ideologia ou ciência, seus impensados, seus não-ditos, seus silêncios, conscientes ou não, seus eventuais recalques críticos. Tudo o que As palavras e as coisas dizem sobre o retorno, na linguagem, do silenciado do ser, uma espécie de hermenêutica do silêncio etc. parece-nos encontrar um eco manifesto na estética e na epistemologia de Didi-Huberman. 0 tipo de gesto que restitui a palavra aos silenciados da história vai 
beneficiar inúmeros autores. Tomemos um exemplo, fascinante, desse viés foucaultiano. Ele confirma a dimensão genealogista e hermenêutica da empreitada didi-hubermaniana, que procura redesenhar e reconfigurar, a partir de fontes e matrizes "intempestivas" ou "an-acrônicas", o platô da epistemologia e da inteligência da arte. Trata-se do lugar reservado a Plínio, o Velho, em Diante do tempo. A que "serve" Plínio, autor do século 1?

Ao analisar o famoso Livro XXXV da História Natural consagrado às "imagines pictae", Didi-Huberman encontra no autor romano uma "antropologia da semelhança que transborda de todos os lados o ponto de vista "disciplinar" da história da arte humanista" (Didi-Huberman, 2000: 70). Ao afirmar que a imaginum pictura - a impressão em cera do rosto de um ancestral cuja máscara mortuária presidirá depois a vida cotidiana da família na parede da domus - é, antes, "o encontro árido de uma matéria e de um rito" (Ibidem: 68) familiar e social, ele mostra que duas concepções da imagem, muito distantes no tempo - 15 séculos -, fundaram duas perspectivas teóricas sobre "a arte". A História tem dois começos, duas inaugurações, a pliniana e a vasariana. Ao contrário de Vasari - cuja história e teoria pressupõem "o caráter [sempre] artístico da representação visual" (Ibidem: 68), uma certa ideia da pintura, uma história evolutiva, a concepção da história e da teoria da arte como "saber "específico" e "autônomo" dos objetos figurativos" (Ibidem: 61) -, Plínio apresenta uma concepção não temporalizada, não teleológica da produção icônica. Plínio fala de materiais modestos, pobres, de gestualidades mais artesanais, populares, de circulação socialmente mais ampla. A concepção da imagem segundo Plínio, - Velho, pertence a um "culto genealógico"; a vasariana, a uma "cultura estética" (Ibidem: 69). Essa diferença, que determina uma maneira oposta de gerir a semelhança entre a imagem antropológica e juridicamente eficaz (a imago pliniana) e a obra entendida como artifício (em Vasari), define uma radical "diferença ética" (Ibidem: 71). Tal antropologia da imagem, em torno da dignidade da imago e da indignidade da "luxúria" nas pinturas arrojadas (segundo Plínio) ${ }^{10}$, constitui uma arqueologia e uma genealogia de outro olhar e de outro discurso sobre a arte em geral; constitui a caução crítica, o modelo operacional e discursivo dos livros mais "livres" cujos subtítulos mencionamos há pouco, sendo eles todos consagrados àquilo que a iconologia desprezaria porque não privilegia motivos de grande iconografia.

Desde as origens, a obra de Didi-Huberman testemunha a força ativa de uma constelação sempre mais densa de autores oriundos da filosofia, da literatura, da antropologia, da história etc. Quando falamos em origem, é porque não existe obra que manifeste com mais evidência o mecanismo de capilaridade metodológica e epistemológica de seus conceitos basilares que a de Didi-Huberman. A relação entre repetição e diferença, evocada no início desse texto, parece sustentar a exigência de uma historiografia em constante processo de reafirmação de seus partidos filosóficos, contidos na famosa definição da origem por Walter Benjamin. Se uma obra testemunha a fertilidade do devir, é bem a de Didi-Huberman, que nunca deixa seus subsolos secarem, que nunca deixa de realimentar a força do fluxo inicial. É o que acontece por meio da constelação constituída por Freud, Benjamin, Bataille, Carl Einstein, Warburg, que desempenha um papel mediador e cristalizador. Vivem, sobrevivem, aparecem e reaparecem; nunca morrem. São origens em constante devir. Falemos um pouco dos dois últimos, para findar nosso texto.

\section{Gigue}

Com Carl Einstein e Aby Warburg, o intenso trabalho de redescoberta e reabilitação de autores esquecidos, negligenciados, ou equivocadamente interpretados pela historiografia predominante, confirma Didi-Huberman como hermeneuta dos recalques historiográficos. No caso de Einstein, 0 apagamento de sua obra testemunharia, pensa, o mal-estar de uma historiografia perante "um 
pensamento essencialmente multifocal" (Didi-Huberman, 1998b: 31) cuja radicalidade teria sido inassimilável pela historiografia. "Relê-lo hoje é reencontrar (...) um contato direto com a parte maldita [la part maudite] da história da arte" (Ibidem: 32). O preço do recalque é "um esquecimento, por mais parcial que fosse, de suas raízes metodológicas" (Ibidem: 33). Didi-Huberman identifica em C. Einstein um projeto crítico e epistemológico revolucionário. Parece, inclusive, ao leitor de hoje que, ao falar dele, ao elogiar sua visão crítica, Didi-Huberman faz novamente, em negativo, seu autorretrato. Com efeito, poderíamos substituir o nome de Didi-Huberman ao de Einstein quando afirma que o historiador alemão

nunca acreditou que a compreensão das imagens de arte pudesse se satisfazer de um saber específico, de um saber legitimado por sua própria cerca disciplinar. (...) É em todos os fronts do pensamento que a imagem exige ser provada, analisada, e é bem em todos os fronts do pensamento que Carl Einstein terá intentado prestar conta [dessa exigência] (Ibidem: 33).

Autorretrato... Se Didi-Huberman destaca o primeiro "aforismo metódico" da série publicada por Einstein na revista Documents em 1929 - "a história da arte é a luta de todas as experiências ópticas, dos espaços inventados e das figurações" (Ibidem: 35$)$ - é bem para transformá-lo implicitamente em epígrafe da sua obra. Esse aforismo poderia também dar conta do espírito da obra de uma outra figura tutelar que vai acompanhá-lo durante longos anos: Aby Warburg.

Em função de uma certa vulgata que transforma o modelo ou anti-modelo do "atlas" em fiador, sem direito à voz, de repetidas exposições na forma de montagens de arquivos ou imagens que projetam (pseudo-?)sistemas de "memória" muitas vezes aleatórios, Warburg precisa ser redimensionado e subtraído a seu atual uso epigonal. Uma parte potente da obra de Didi-Huberman, já iniciada no fim dos anos 1990, com um ápice no início dos anos 2010, é consagrada aos possíveis desdobramentos de sua obra singular. Didi-Huberman não o teria "encontrado" sem a existência de um solo solidamente fundamentado, que preparou sua recepção de maneira que podemos qualificar de imanente. São duas paixões pelas imagens que encontramos no mestre do início do século XX e no do início do século XXI..., paixões pelas imagens vivas, movimentadas, turbulentas.

Na abertura que fez numa das sessões do Seminário Georges Didi-Huberman (2016), na Unicamp, o professor, Jorge Coli identificou uma ausência propositiva de "fórmulas de ataraxia" na estética warburguiana. Sugeriu que o privilégio dado por Warburg às "fórmulas de pathos" poderia ser interpretado como uma recusa manifesta da estética clássica winckelmanniana (o Belo como Harmonia), a qual reinava como norma na historiografia de sua época. (Consideramos essa proposição como pertinente e plenamente aplicável a Didi-Huberman, tampouco interessado em possíveis "fórmulas de ataraxia") ${ }^{11}$. Assim, a "chegada" de Warburg na obra de Didi-Huberman já era possível como conceito imanente de seu pensamento e de sua pesquisa quando ele inaugurava sua obra com o estudo da histeria, quando se debruçava sobre o "fantasma de sangue" na pintura, quando intentava demolir a iconologia humanista e substituí-la por uma "antropologia do visual" - termo programático presente em Diante da imagem -, ou quando apresentava no livro sobre Georges Bataille a "dessemelhança informe" através de fotografias de panos de chão nas calçadas parisienses... Se Panofsky serviu de contra-modelo e antítese para construir, pela negação, uma posição epistemológica, Warburg serviu de paradigma metodológico para a construção de uma tese positiva. Serviu, como o filtro de amor no Tristão de Wagner, de agente de cristalização. (Mas antes, tivemos Carl Einstein e Georges Bataille) $)^{12}$. 
Warburg é um mestre por muitas razões: ensinou a Didi-Huberman, mas, antes, à História da arte, uma nova filosofia do tempo, da temporalidade das imagens. Poderíamos citar muitas frases de $A$ imagem sobrevivente, para mostrar como isso é central. A temática complexa de Nachleben etc. exige uma dialética do tempo, das formas, que Didi-Huberman problematiza intensamente, reafirmando a necessidade de todo historiador assumir também uma posição filosófica. Outro ponto central é o fato de Warburg ensinar ao historiador como renovar completamente o exercício do olhar, seu olhar de profissional sobre as imagens. Warburg, no final de contas, é um mestre da percepção e Didi-Huberman é o grande reintrodutor da urgência da percepção na análise das obras, na organização e evidenciação daquilo que elas dão a ver. Didi-Huberman tem com as imagens e a arte em geral uma empatia absolutamente impressionante, os livros-tesouros que mencionamos anteriormente sendo o emblema dessa capacidade de ver - e de escrever sobre os mais complexos comportamentos plásticos. Modelo operacional de caráter intuitivo, o "atlas" serve a repensar os prolongamentos da intuição e da percepção; induz à montagem, gera uma atenção inédita do historiador sobre seu material, uma estética que exige movimentar e submeter a uma outra lógica a reprodução das imagens.

O historiador deve se tornar um pouco artista ou, pelo menos, exercer a responsabilidade estética do seu olhar. Na hora da investigação, ao "montar" um anti-sistema sistêmico e singularmente autoral de imagens selecionadas por suas afinidades morfológicas e expressivas, o historiador da arte compartilha com 0 artista uma experiência. Warburg autoriza a experiência renovada do historiador. Nesse sentido, o "modelo"-Warburg de organização das imagens é o modelo da licença, para o historiador, de determinar por si só sua experiência com elas e de fazer dessa experiência um ponto inicial e um ponto de fuga da pesquisa. É também o que gostaríamos de chamar, paradoxalmente, de faculdade de improviso lógico que fascina os artistas no "modelo"-Warburg de montagem das imagens. A reinvenção da experiência do historiador é um ponto central da obra de Didi-Huberman. 0 historiador neowarburguiano e didi-hubermaniano não mergulha friamente na História da arte para trabalhar mais uma vez as mesmas balizas. Ele não se contenta em privilegiar os portais monumentais das referências distribuídas pela posteridade. Ele regride, de certa maneira, num solo em forma de tabuleiro, para proceder aos deslocamentos que seu saber o pré-determina a realizar, mas também para seguir o que sua intuição convida-o a realizar. Talvez, a moral da obra resida numa frase do livro publicado em 2015 sobre Jean-Luc Godard, no qual Didi-Huberman tem um prazer evidente em opor a ética e a empatia de Pasolini com o povo ao cinismo autoritário de Godard. Mais uma vez, no mosaico do texto, temos uma maneira de autorretrato:

Como Aby Warburg, que tinha feito da tradição clássica o lugar de todas as "instabilidades" e de todas as inquietudes semânticas, Pasolini terá procurado na arte do passado - desde a tragédia grega até Caravaggio, passando por Bocaccio ou Masaccio - os princípios de uma transgressão das linguagens, verbais e figurativas, que o conformismo dos tempos presentes fixou. Para Godard, é o passado que é conformista, e quando ele cita uma frase ou uma forma antigas, é para pronunciar sua obsolescência ou para desconstruir sua autoridade. Pasolini, ao contrário, cita para fazer reescutar a energia sobrevivente daquilo que não quis morrer (o dialeto napolitano, por exemplo, ou uma composição de Giotto) (Didi-Huberman, 2015: 188).

Caçar as instabilidades na tradição clássica, fazer reescutar a energia sobrevivente daquilo que, no passado, foi tudo, menos conformista, é o que Didi-Huberman faz na sua obra. Ele terá, portanto, assumido uma postura godardiana - pronunciar algumas obsolescências e descontruir algumas autoridades - e pasoliniana. Mas entre uma posição de autoridade e a "fecundidade heurística" (DidiHuberman, 2015: 30), ele escolheu a segunda, a "autoridade" de sua obra decorrendo de um trabalho paciente, imensamente paciente, expositivo e até didático de sensibilização argumentativa. Nesse 
sentido, ele é mais próximo da maiêutica socrática do que da filosofia dos filósofos que martelam ou impõem uma autoridade afogadora. Didi-Huberman descobre territórios e redes conceituais sempre mais diversos e abrangentes, sem nunca perder de vista seu eixo e a interlocução com o leitor. É o selo das grandes obras: sua necessidade interior.

\section{Addendum sobre a sequência...}

Quando este texto foi escrito, no fim de 2016, Georges Didi-Huberman, curador, apresentou a famosa exposição Soulèvements na Galeria do Jeu de Paume em Paris. Muito comentada, ela mostrava imagens "ilustrando" vários levantes sócio-políticos na História, com a ideia de elas todas serem constelações icônicas e dialéticas sobre o fervilhamento das rebeldias populares. Essa dimensão mais literalmente política da pesquisa didi-hubermaniana não aparece no texto que publicamos aqui. Para ter uma ideia de sua importância atual, é preciso entender que o trabalho sobre 0 olho da história gerou uma abordagem caracteristicamente política sobre o poder, ele mesmo político, das imagens. 0 seminário de Didi-Huberman iniciado no fim dos anos 2000 sobre as figuras icônicas do "povo" está se prolongando hoje numa reflexão baseada no contexto alemão dos anos posteriores a 1918. O intuito é o de perguntar que modelo de tempo os artistas e filósofos daquela época seguiam quando proclamavam a necessidade de renovar a época. Posto sob a invocação da fórmula: "il est grand temps" (é hora de, urge, é tempo de...), Didi-Huberman prepara, desde 2016, o terreno para a entrada em cena de um filósofo que bem poderia se revelar a figura central dos anos atuais e vindouros: o messiânico Ernst Bloch, que nos ensinaria o Princípio Esperança em tempos de tensões e desencanto. Quanto mais Didi-Huberman se confronta às questões políticas, mais filósofo se torna: assim ressoa o anfiteatro "Aby Warburg" do INHA (Instituto Nacional de História da Arte)... Quem quiser entrar na intensidade da pesquisa atual pode ler o livro publicado em fevereiro de 2019, Désirer désobéir. Ce qui nous soulève, 530 páginas de texto e 115 páginas de bibliografia! 0 título pode ser lido como: desejar desobedecer, já que a ausência de pontuação entre os dois verbos não autoriza verdadeiramente a inclusão de um "e" entre eles (desejar e desobedecer). Política e/do desejo.

\section{Referências}

COLI, J. Polaridades e anacronismos no pensamento de Warburg. MODOS. Revista de História da Arte. Campinas, v. 1, n.2, p.09-21, mai. 2017. Disponivel em: <https://doi.org/10.24978/mod.v1i2.755 >.

DIDI-HUBERMAN, Georges. La peinture incarnée, suivi de Le chef-d'œuvre inconnu par Honoré de Balzac. Paris: Les éditions de Minuit, 1985. (A Pintura Encarnada, seguido de A obraprima desconhecida de Honoré de Balzac. São Paulo: Editora da Fap-Unifesp/Editora Escuta. Tradução de Osvaldo Fontes Filho e Leila de Aguiar Costa, 2012).

Le Cube et le visage. Autour d'une sculpture d'Alberto Giacometti. Paris: Macula, 1993.
L'Empreinte. Catálogo de exposição. Paris : Centre Georges Pompidou, 1997.

. L'Étoilement. Conversation avec Simon Hantaï. Paris : les éditions de Minuit, 1998a.

L'anachronisme fabrique l'histoire de l'art: sur l'inactualité de Carl Einstein. In: Études Germaniques: Revue de la Société des Études Germaniques, LIII, Paris: Didier érudition, janvier-mars, 1998b. (Retomado no capítulo L'image-combat. In: Devant le temps (2000).

Fra Angelico: Dissemblance et figuration. Paris: Flammarion, col. Champs, 1990a.

Devant l'image. Questions posées aux fins d'une histoire de l'art. Paris: Les éditions de Minuit, 1990b. (Diante da imagem: Questões 
postas aos fins de uma história da arte. São Paulo: Ed. 34, 2013).

Régions de dissemblance. Catálogo de
exposição, Musée Départemental de
Rochechouart, 1990c.

Phasmes. Essais sur l'apparition. Paris: Les éditions de Minuit, 1998c.

Devant le temps: Histoire de l'art et anachronisme des images. Paris: Éditions de Minuit, 2000. (Diante do tempo. História da arte e anacronismo das imagens. Belo Horizonte: Editora UFMG. Tradução de Márcia Arbex e Vera Casa Nova, 2015).

Ser crânio. Lugar, contato, pensamento, escultura. Belo Horizonte : C/Arte. Tradução de Augustin de Tugny e Vera Casa Nova, 2009. (Être crâne. Lieu, contact, pensée, sculpture. Paris: L es éditions de Minuit, 2000).

L'image survivante: Histoire de l'art et temps des fantômes selon Aby Warburg. Paris: Les éditions de Minuit, 2002. (A imagem sobrevivente. História da arte e tempo dos fantasmas segundo Aby Warburg. São Paulo: Contraponto, 2013).
Sobrevivência dos vaga-lumes, Belo Horizonte: Editora UFMG. Tradução de Vera Casa Nova e Márcia Arbex, 2011. (Survivance des lucioles. Paris: Éditions de Minuit, 2010.).

"Quadro = Corte' - Experiência Visual, Forma e Sintoma segundo Carl Einstein" [1996]. In: HUCHET, Stéphane (org.). Fragmentos de uma teoria da arte. São Paulo: Edusp, 2012, p. 61-95.

. Passés cités par JLG. L'œil de l'histoire, 5. Paris: Les éditions de Minuit, 2015.

Désirer désobéir: Ce qui nous soulève, 1. Paris: Les éditions de Minuit, 2019.

PANOFSKY, Erwin. Idea. A evolução do conceito de Belo. São Paulo: Martins Fontes, 2000.

SCHAEFFER, Jean-Marie. L'art de l'âge moderne: L'esthétique et la philosophie de l'art du XVIIlème siècle à nos jours. Paris: Gallimard (NRF essais), 1992.

SEMINÁRIO GEORGES DIDI-HUBERMAN 2016. Campinas. Instituto de Artes da Unicamp. 22 e 23 nov. 2016. Disponivel em: $<$ https://www.iar.unicamp.br/evento/seminariog dh2016/>. Acesso em: maio 2020.

\section{Notas}

\footnotetext{
* Stéphane Huchet. Professor Titular. Escola de Arquitetura. Universidade Federal de Minas Gerais. Pesquisador do CNPq. E-mail: <st.huchet@gmail.com>. ORCID: <https://orcid.org/0000-0003-4102-6920>.

${ }^{1}$ Mas, antes deles, a historiografia francesa já tinha criado um campo de estudos no qual a dimensão culturalista da arte motivava ótimos trabalhos. Não podemos negar a importância e o valor dos trabalhos de André Chastel, Robert Klein e Pierre Francastel como sociólogos da arte. Entretanto, o método e o discurso historiográfico se mostravam ainda dependentes da iconologia. Panofsky era a figura tutelar da disciplina, um superego dificilmente contestável.

2 Quando veremos editoras engajadas traduzir A teoria da nuvem (Damisch, 1972) e Détruire la peinture (Marin, 1977)?

3 Sabemos a importância que a montagem tem na obra de Didi-Huberman, como o paradigma warburguiano do "atlas" Ihe devolveu força, como ela representa uma maneira que as imagens têm de "tomar posição" (Ver Quand les images prennent position, 2009).

4 É também o caso quando desloco a interpretação do "método da dobra" em Hantaï para o campo epistemológico de Didi-Huberman: trata-se de dobrar uma superfície, um campo, de tal maneira que o desdobramento seja sua movimentação; criar, portanto, uma percepção que saiba fazer durar a perceptibilidade do processo (p. 80-81). A insistência didi-hubermaniana em certos pontos críticos decorre da necessidade de fazer durar a argumentação e as certezas - sim - adquiridas no campo de ressonância de conceitos paciente e longamente problematizados.

${ }^{5}$ Que o leitor não se engane: aqui, trata-se da oposição entre iconografia, com a letra "o", e icnografia. "Icnografia" vem do grego Ichnos, traço. As reformas da língua portuguesa retiraram a letra "h", o que gera confusão porque o leitor pode pensar que 0 autor queria escrever "iconografia", mas que ele esqueceu a letra "o"! Não. A manutenção da letra "h" é uma tática recomendável para evitar o erro. Temos bem de um lado a "iconografia" e, de outro lado, a "ic(h)nografia", dimensão mais matérica e material.

${ }^{6} \mathrm{Na}$ pintura do Angelico, são as manchas vermelhas espalhadas na grama ao pé de Cristo (Noli me tangere), uma grande mancha luminosa na Anunciação ou os marmori finti debaixo da Madona, no mesmo convento de São Marco, em Firenze (Didi-Huberman teve seus mitos originários).

${ }^{7}$ Doze anos mais tarde, o livro sobre Warburg retomará essa temática, envolvendo-a numa rede de referências bem maior, mas a tese será a mesma: a História da arte e a doutrina artística propostas por Winckelmann permitem repetir a crítica do tom metafísico próprio à disciplina, e Panofsky assume novamente o papel do vilão, já que ele procedeu, desde os anos 1930, ao recalque de Warburg, isto é, ao silenciamento de uma voz perturbante para as certezas da disciplina.
} 
${ }^{8} \mathrm{Em} / \mathrm{dea}$ (1924), Panofksy procede a uma análise exaustiva do papel desse conceito (neo)platônico na Teoria da arte, da Antiguidade até o neoclassicismo. É um livro insubstituível para entender como a História e Filosofia da arte são indissociavelmente associadas. ${ }^{9}$ A identificação da primazia de uma metafísica da imagem na Teoria clássica da arte constitui, dentro do campo ainda disciplinar da História da arte, um eco convergente à identificação, no campo da Filosofia da arte, da arte como conhecimento especulativo. Um filósofo da arte de grande peso, Jean-Marie Schaeffer, lembra em L'art de l'âge moderne (1992) que a maioria das doutrinas estéticas dos séculos XIX e XX foram ontologias da arte entendida como revelação do Ser etc. Se aderirmos à ideia de que certo platonismo, muitas vezes reelaborado, vigorou, tanto na teoria quanto na filosofia da arte, entre Vasari e Martin Heidegger, vemos que o trabalho de crítica realizado por Didi-Huberman em Diante da imagem é central.

10 Em Diante do tempo, Didi-Huberman menciona a recorrência de uma terminologia depreciativa em vários momentos da História natural. A noção de luxúria avizinha as de delícias, desejos, raiva, "cupiditas", obscenidade, insânia. Todas contribuem para Plínio, 0 Velho, exprimir "a decadência" em que a arte se encontraria quando se perde de vista a dignidade da imago.

11 Infelizmente, as comunicações desse Seminário (22 e 23 de novembro de 2016) não foram publicadas. 0 professor Coli falou na tarde do dia 23. 0 artigo aqui publicado retoma a palestra que apresentei no dia 22. Uma versão do texto de Coli foi publicada na Revista MODOS (Coli, 2017).

${ }^{12}$ Ao ver como, nos seus primeiros livros, Didi-Huberman demonstrava um prazer tão grande em apresentar o que lhe ocorreu frente a tal ou tal obra, imagem ou objeto, como ele se deixava surpreender, encantar, seduzir etc., medimos até que ponto o misto de consciência e de Stimmung (disposição receptiva e empática) próprio ao olhar warburguiano destinava-o a encontrar em Warburg um mestre insuperável.

Artigo recebido em maio de 2020. Aprovado em agosto de 2020. 